\title{
Bending Analysis of Functionally Graded Nanobeam Using Chebyshev Pseudospectral Method
}

\author{
Nurettin Şenyer ${ }^{a}$, Nihat Can ${ }^{b}$, İbrahim Keles ${ }^{c^{*}}$ \\ ${ }^{a}$ Samsun University, Faculty of Engineering, Department of Software Engineering, Samsun, Turkey \\ ${ }^{b}$ Ondokuz Mayls University, Faculty of Engineering, Department of Mechanical Engineering, Samsun, Turkey \\ ${ }^{c}$ Samsun University, Faculty of Engineering, Department of Mechanical Engineering, Samsun 55080, Turkey \\ "E-mail address: ibrahim.keles@samsun.edu.tr
}

ORCID numbers of authors:

0000-0002-2324-9285 ${ }^{a}$, 0000-0002-5741-0890 ${ }^{b}, 0000-0001-8252-2635^{c}$

Received date: 15.12 .2021

Accepted date: 30.12 .2021

\begin{abstract}
Static performance of functionally graded cantilever nanobeams exposed to lateral and axial loads from the end was examined by applying the Pseudospectral Chebyshev Method. A solution is given for bending analysis using Euler-Bernoulli beam theory. The nonlocal elasticity theory was first introduced by Eringen and is used to represent effect on a small scale. Using the aforementioned theory, the governing differential equations the phenomenon for functionally graded nanobeams are reproduced. It is supposed that the modulus of elasticity of the beam changes exponentially in the $x$-axis direction, except for the values taken as constant. The exponential change of material properties may not allow analytical problems to be solved with known methods. Therefore, numerical approach is inevitable for the solution of the problem.
\end{abstract}

Keywords: Nonlocal elasticity theory, nanobeam, Chebyshev pseudospectral method, bending analysis

\section{Introduction}

Functionally graded materials (FGMs) have gained wide application in different industrial areas due to varying toughness and other material properties in the form of graded functions along certain dimensions. In order to have two opposite properties such as high thermal conductivity and high thermal resistance, which are found in FGMs, in a material, a lot of research has been done in the literature for static, buckling and dynamic conditions in order to lightness, strength and durability $[1,2,11-15,3-10]$.

With the rapid advancement of technology, FGMs have begun to be used in applied engineering fields in micro or nanoscale structures[14]. These materials, which have superior technical and physical properties, are of great importance in the pharmaceutical industry, especially with their use in electrically operated Micro-Electro-Mechanical Systems (MEMS)[16] and atomic force microscopes (AFMs) [17]. 
The size effect is extremely important in mechanical calculations of nano and micro-size constructions. Conventional elasticity technique cannot be used to explain the size effect since there is no material length size parameter. There are different non-traditional continuity assumptions to explain the size-dependent effect. Some of these theories include modified strain change, non-local elasticity, modified stress couple theories. Eringen [16] and Eringen and Edelen [17] first addressed the non-local elasticity principle in their research. This theory is frequently used in dissection mechanics, wave distribution, fracture mechanics, beam-type structures [18-20] and plate-type structures [21-23]. According to the non-local elasticity theory, many academic studies have been conducted in recent years. Some of these are [24-29] [8-13]. Wang et al. [30] addressed the vibration and bending problem in carbon nanotube using the beam-shell relationship and nonlocal elastic structure equations. A comprehensive analytical method for solving the fourth-order differential equation related to the bending analysis of bidirectional functional grade nanobeams obtained by Eringen's nonlocal elasticity theory is presented by Nazmul and Devnath[31]. Akgöz et al.[32] investigated the thermoelastic vibrational behavior of thick microbeams based on elastic foundation with modified double stress theory. Dastjerdi and Akgöz[33] used 3D elasticity theory together with nonlocal theory to study the static and vibrational behavior of FG circular nanoplates. Akgöz and Civalek[34] utilized the double stress theory for the static and stability analysis of single-walled carbon nanotubes applying different theories. Different method was used for the analysis of micro- or nano-scale mechanical systems under different conditions in[35]. Civalek and Kiracioglu[36] applied the discrete singular convolution method for the numerical solution of the Timoshenko beam's equation of motion. Some studies[37,38] have established a nonlocal finite element method for thin beams.

The nonlocal parameter $\left(e_{0} a\right)$ captures the small-scale effects on the response of structures in nano-size; $e_{0}$ is called the nonlocal material constant, and a is the internal scale parameter. In the previous studies related to nano functionally graded materials, the nonlocal parameter is generally assumed as a constant. A conservative estimation of the nonlocal parameter $0<e o a$ $<2 \mathrm{~nm}$ for single-walled carbon nanotubes is suggested by Wang[39]. Therefore, in this study, the nonlocal parameter is taken as $e o a=1 \mathrm{~nm}$ to investigate bending analysis on the responses of functionally graded nanobeam.

In this study, bending analysis of functionally graded cantilever nanobeams as well as extreme intense loads using modified stress couple and Pseudospectral Chebyshev Method (PCM) is discussed. A system of differential equalities is obtained with early and limit conditions. PCM with known initial conditions is used to these systems of differential equalities including nonlocal elasticity parameter. The precision of the proposed technique was confirmed using the literature, then the outcomes were graphically shown and discussed according to the calculations obtained.

\section{Theory and Formulations}

The geometric fitness condition, equilibrium equations and constitutive relations of the FG nano beam in the two-dimensional plane are as follows[40,41]

$$
\begin{gathered}
\frac{d w}{d x}=\varphi \\
\frac{d \varphi}{d x}=-\frac{M}{E(x) I}
\end{gathered}
$$




$$
\begin{gathered}
\frac{d M}{d x}=P_{1} \varphi+T \\
\frac{d T}{d x}=0
\end{gathered}
$$

where $T$ and $M$ are the shear force and the bending moment, $\varphi$ and $w$ are the slope of the FG nano beam and the lateral displacement. Also, $I$ is moment of inertia, the elasticity modulus varies corresponding to the function given in the equation $E(x)=E_{1} e^{-\lambda x}$ [42], here $\lambda$ is inhomogeneity parameter.

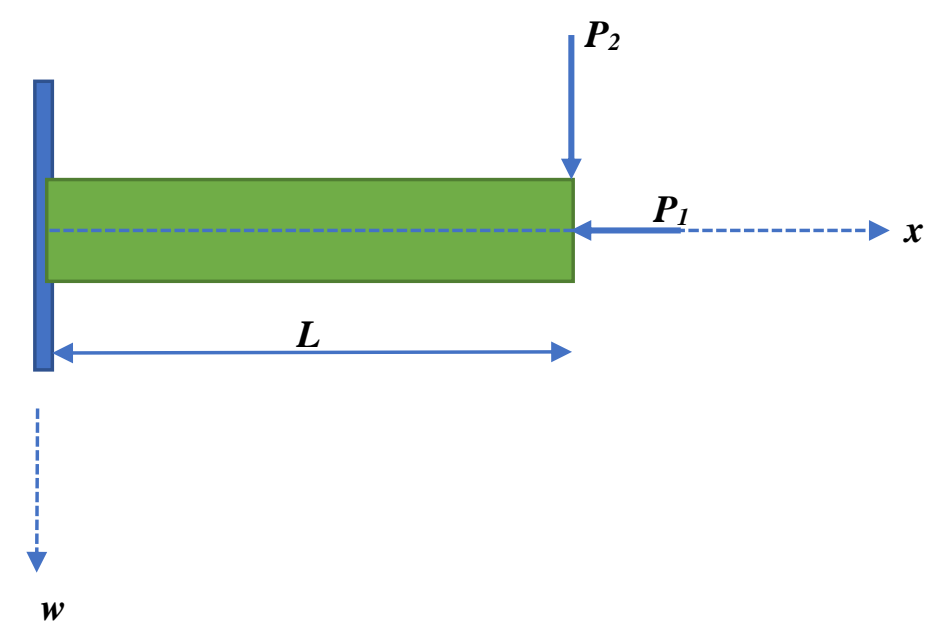

Fig. 1. Cantilever nano-beam with lateral and axial forces[32]

The final form of Eq.(2) according to the nonlocal elasticity theory takes the following form[43]

$$
M-\left(e_{0} a\right)^{2} \frac{d^{2} M}{d x^{2}}=-E(x) I \frac{d^{2} w}{d x^{2}}
$$

where $\mathrm{a}$ is the inner typical length, is a constant $\left(e_{0}=0.39, a=4 * 10^{-8} \mathrm{~cm}\right)$. Using Eq. (2), above relation takes the following form

$$
M=E(x) I\left[1-\left(e_{0} a\right)^{2} \frac{P_{1}}{E(x) I}\right] \frac{d \varphi}{d x}
$$

The final form of the governing differential equations the situation is given as:[40,41]

$$
\frac{d}{d x}\left[\begin{array}{c}
W \\
\varphi \\
M \\
T
\end{array}\right]=\left[\begin{array}{cccc}
0 & 1 & 0 & 0 \\
0 & 0 & \frac{-1}{E(x) I\left[1-\left(e_{0} a\right)^{2} \frac{P_{1}}{E(x) I}\right]} & 0 \\
0 & P_{1} & 0 & 1 \\
0 & 0 & 0 & 0
\end{array}\right]\left[\begin{array}{c}
W \\
\varphi \\
M \\
T
\end{array}\right]
$$

where $P_{1}$ the axial force, $P_{2}$ the side force, the inner typical length and $e_{0}$ is a constant. The primary conditions are given below;

$$
\begin{aligned}
& w(0)=0 \\
& \varphi(0)=0
\end{aligned}
$$




$$
\begin{gathered}
M(0)=-P_{2} L \\
T(0)=P_{2}
\end{gathered}
$$

From Eq. (7), the following expressions are obtained;

\section{Solution Procedure}

$$
\begin{gathered}
\frac{d w}{d x}=\varphi \\
\frac{d \varphi}{d x}=-\frac{M}{E(x) I\left[1-\left(e_{0} a\right)^{2} \frac{P_{1}}{E(x) I}\right]} \\
\frac{d M}{d x}=P_{1} \varphi+T \\
\frac{d T}{d x}=0
\end{gathered}
$$

This section is where PCM is applied to discretize the main equalities and boundary conditions and transform them in algebraical equalities. This model is utilized to execute the evaluation of the static performance of the FG nanobeam by reference to the work of Trefethen[44], Fornberg[45] and Gottlieb[46]. It depends on a discretization of the main equalities with respect to the spatial variable. With regard to collocation points, the initial order $(n+1) \times(n+1)$ Chebyshev differentiation matrix

$$
0=x_{0}<x_{1} \ldots<x_{n} \text { with } x_{j}=\frac{1}{2}\left[1-\cos \left(\frac{j \pi}{n}\right)\right]
$$

$(j=0,1, \ldots, n)$ will be represented by $D$. First-order Chebyshev differentiation matrix D offers a very precise approximation to $V^{\prime}{ }_{n}\left(x_{j}\right), V^{\prime \prime}{ }_{n}\left(V_{j}\right) \ldots$, simply by multiplying differential matrix with vector data:

$$
\left[\begin{array}{c}
\frac{d V_{n}}{d x}\left(x_{0}\right) \\
\frac{d V_{n}}{d x}\left(x_{1}\right) \\
\vdots \\
\frac{d V_{n}}{d x}\left(x_{n}\right)
\end{array}\right] \approx D\left[\begin{array}{c}
V_{n}\left(x_{0}\right) \\
V_{n}\left(x_{1}\right) \\
\vdots \\
V_{n}\left(x_{n}\right)
\end{array}\right],\left[\begin{array}{c}
\frac{d^{2} V_{n}}{d x^{2}}\left(x_{0}\right) \\
\frac{d^{2} V_{n}}{d x^{2}}\left(x_{1}\right) \\
\vdots \\
\frac{d^{2} V_{n}}{d x^{2}}\left(x_{n}\right)
\end{array}\right] \approx D^{2}\left[\begin{array}{c}
V_{n}\left(x_{0}\right) \\
V_{n}\left(x_{1}\right) \\
\vdots \\
V_{n}\left(x_{n}\right)
\end{array}\right]
$$

Details on the calculation of the Chebyshev differentiation matrix and codes as m-files can be discovered in remarkable references, e.g. Trefethen[44].

By using the Chebyshev differential matrix, derivatives of any order can be easily discretized. The final form of Eqs. (12-15) is written in the form below:

$$
L_{w} w=0
$$

where $L_{w}=D-\frac{\varphi}{w}$

$$
L_{\varphi} \varphi=0
$$

$$
\begin{array}{r}
\text { where } L_{\varphi}=D+\frac{M}{\varphi E(x) I\left[1-\left(e_{0} a\right)^{2} \frac{P_{1}}{E(x) I}\right]} \\
L_{M} \varphi=0 \\
L_{M}=D-\frac{P_{1}}{M} \varphi+\frac{T}{M}
\end{array}
$$




$$
L_{T} T=0
$$

where $L_{T}=D$

To get the non-trivial solution, the boundary conditions (8-11) for the bending analysis are imposed on this linear system (18-21) with replacing just the initial and last row of the linear operators $\left(L_{w} ; L_{\varphi} ; L_{M} ; L_{T}\right)$ with the appropriate values and the values corresponding to the function on the right.

\section{Validation of the Present Results}

For the efficiency and reality of the numerical method, when the solutions are performed by taking zero instead of $\lambda$ in the cantilever FG nano beam, which is taken as $E(x)=E_{1} e^{-\lambda x}$ [42], the cantilever nano beam, which has been solved in the literature[32]will be in a homogeneous state. $\mathrm{E}_{1}=1 \mathrm{nN} / \mathrm{m}^{2}, \mathrm{e}_{0} \mathrm{a}=1 \mathrm{~nm}, \mathrm{I}=1 \mathrm{~nm}^{4}$ and $\mathrm{P}_{2}=1.0 \mathrm{nN}$ are taken in all calculations. In Table 1, the static deviation values of the homogeneous cantilever nano beam are given by using the material properties $\mathrm{E}(x)=E_{1} e^{-\lambda x}$ and taking $\lambda=0$. It has been observed that the displacement values obtained by PCM correspond exactly to the findings in the literature[32].

Table 1. Comparison of the static deflection $(w)$ values with PCM solutions and the results in the literature [32] for a homogeneous cantilever beam

\begin{tabular}{|c|c|c|c|c|c|c|}
\hline \multirow[b]{2}{*}{$x$} & \multicolumn{2}{|c|}{$\mathrm{P}_{2}=1.0 \mathrm{nN}$} & \multicolumn{2}{|c|}{$\mathrm{P}_{2}=1.2 \mathrm{nN}$} & \multicolumn{2}{|c|}{$\mathrm{P}_{2}=1.4 \mathrm{nN}$} \\
\hline & PCM & Ref. [32] & PCM & Ref. [32] & PCM & Ref. [32] \\
\hline 0.0 & 0.00017 & 0.00017 & 0.00020 & 0.00020 & 0.00024 & 0.00024 \\
\hline 0.1 & 0.00467 & 0.00467 & 0.00561 & 0.00561 & 0.00655 & 0.00655 \\
\hline 0.2 & 0.01846 & 0.01846 & 0.02215 & 0.02215 & 0.02585 & 0.02585 \\
\hline 0.3 & 0.04013 & 0.04013 & 0.04816 & 0.04816 & 0.05618 & 0.05618 \\
\hline 0.4 & 0.06828 & 0.06828 & 0.08194 & 0.08194 & 0.09560 & 0.09560 \\
\hline 0.5 & 0.10153 & 0.10153 & 0.12183 & 0.12183 & 0.14214 & 0.14214 \\
\hline 0.6 & 0.13846 & 0.13846 & 0.16615 & 0.16615 & 0.19384 & 0.19384 \\
\hline 0.7 & 0.17768 & 0.17768 & 0.21322 & 0.21322 & 0.24876 & 0.24876 \\
\hline 0.8 & 0.21780 & 0.21780 & 0.26136 & 0.26136 & 0.30492 & 0.30492 \\
\hline 0.9 & 0.25741 & 0.25741 & 0.30890 & 0.30890 & 0.36038 & 0.36038 \\
\hline 1.0 & 0.29513 & 0.29513 & 0.35415 & 0.35415 & 0.41318 & 0.41318 \\
\hline
\end{tabular}

The tilt of the FG cantilever nanobeam and its effects on the lateral and axial forces applied to the beam are presented in Table 2 . When Table 2 is analyzed, it is seen that the results in the literature are compatible with the current method.

Table 2. Comparison of the slope $(\varphi)$ values for different concentrated forces with PCM solutions and the results in the literature[32] for a homogeneous cantilever beam

\begin{tabular}{ccccccc} 
& \multicolumn{2}{c}{$\mathrm{P}_{2}=1.0 \mathrm{nN}$} & \multicolumn{2}{c}{$\mathrm{P}_{2}=1.2 \mathrm{nN}$} & \multicolumn{2}{c}{$\mathrm{P}_{2}=1.4 \mathrm{nN}$} \\
\cline { 2 - 7 }$x$ & PCM & Ref. [32] & PCM & Ref. [32] & PCM & Ref. [32] \\
\hline 0.0 & -0.00053 & -0.00053 & -0.00064 & -0.00064 & -0.00075 & -0.00075 \\
0.1 & 0.09525 & 0.09525 & 0.11431 & 0.11431 & 0.13336 & 0.13336 \\
0.2 & 0.17895 & 0.17895 & 0.21474 & 0.21474 & 0.25052 & 0.25052 \\
0.3 & 0.25008 & 0.25008 & 0.30010 & 0.30010 & 0.35012 & 0.35012 \\
0.4 & 0.30822 & 0.30822 & 0.36987 & 0.36987 & 0.43151 & 0.43151 \\
0.5 & 0.35292 & 0.35292 & 0.42350 & 0.42350 & 0.49408 & 0.49408
\end{tabular}




$\begin{array}{lllllll}0.6 & 0.38372 & 0.38372 & 0.46047 & 0.46047 & 0.53721 & 0.53721 \\ 0.7 & 0.40020 & 0.40020 & 0.48023 & 0.48023 & 0.56027 & 0.56027 \\ 0.8 & 0.40189 & 0.40189 & 0.48227 & 0.48227 & 0.56264 & 0.56264 \\ 0.9 & 0.38835 & 0.38835 & 0.46603 & 0.46603 & 0.54370 & 0.54370 \\ 1.0 & 0.35915 & 0.35915 & 0.43098 & 0.43098 & 0.50281 & 0.50281\end{array}$

The bending moment of the FG cantilever nano beam and its effects on the lateral and axial forces applied to the beam are presented in Table 3. The effect of lateral and axial force on the bending moment is clearly seen when Table 3 . is examined. The compatibility of the current results with the results in the literature is clearly displayed in Table 3.

Table 3. Comparison of the bending moment $(M)$ values for different concentrated forces with PCM solutions and the results in the literature [32]for a homogeneous cantilever beam

\begin{tabular}{ccccccc} 
& \multicolumn{2}{c}{$\mathrm{P}_{2}=1.0 \mathrm{nN}$} & \multicolumn{2}{c}{$\mathrm{P}_{2}=1.2 \mathrm{nN}$} & \multicolumn{2}{c}{$\mathrm{P}_{2}=1.4 \mathrm{nN}$} \\
\cline { 2 - 7 }$x$ & PCM & Ref. [32] & PCM & Ref. [32] & PCM & Ref. [32] \\
\hline 0.0 & $-1,00 \mathrm{E}-05$ & $-1,00 \mathrm{E}-05$ & $-1,20 \mathrm{E}-05$ & $-1,20 \mathrm{E}-05$ & $-1,40 \mathrm{E}-05$ & $-1,40 \mathrm{E}-05$ \\
0.1 & $-8,94 \mathrm{E}-06$ & $-8,94 \mathrm{E}-06$ & $-1,07 \mathrm{E}-05$ & $-1,07 \mathrm{E}-05$ & $-1,25 \mathrm{E}-05$ & $-1,25 \mathrm{E}-05$ \\
0.2 & $-7,78 \mathrm{E}-06$ & $-7,78 \mathrm{E}-06$ & $-9,33 \mathrm{E}-06$ & $-9,33 \mathrm{E}-06$ & $-1,09 \mathrm{E}-06$ & $-1,09 \mathrm{E}-06$ \\
0.3 & $-6,52 \mathrm{E}-06$ & $-6,52 \mathrm{E}-06$ & $-7,82 \mathrm{E}-06$ & $-7,82 \mathrm{E}-06$ & $-9,13 \mathrm{E}-06$ & $-9,13 \mathrm{E}-06$ \\
0.4 & $-5,18 \mathrm{E}-06$ & $-5,18 \mathrm{E}-06$ & $-6,22 \mathrm{E}-06$ & $-6,22 \mathrm{E}-06$ & $-7,25 \mathrm{E}-06$ & $-7,25 \mathrm{E}-06$ \\
0.5 & $-3,78 \mathrm{E}-06$ & $-3,78 \mathrm{E}-06$ & $-4,54 \mathrm{E}-07$ & $-4,54 \mathrm{E}-07$ & $-5,29 \mathrm{E}-06$ & $-5,29 \mathrm{E}-06$ \\
0.6 & $-2,34 \mathrm{E}-06$ & $-2,34 \mathrm{E}-06$ & $-2,81 \mathrm{E}-06$ & $-2,81 \mathrm{E}-06$ & $-3,27 \mathrm{E}-06$ & $-3,27 \mathrm{E}-06$ \\
0.7 & $-8,68 \mathrm{E}-08$ & $-8,68 \mathrm{E}-08$ & $-1,04 \mathrm{E}-06$ & $-1,04 \mathrm{E}-06$ & $-1,21 \mathrm{E}-06$ & $-1,21 \mathrm{E}-06$ \\
0.8 & $6,14 \mathrm{E}-07$ & $6,14 \mathrm{E}-07$ & $7,36 \mathrm{E}-07$ & $7,36 \mathrm{E}-07$ & $8,59 \mathrm{E}-07$ & $8,59 \mathrm{E}-07$ \\
0.9 & $2,09 \mathrm{E}-07$ & $2,09 \mathrm{E}-07$ & $2,51 \mathrm{E}-06$ & $2,51 \mathrm{E}-06$ & $2,92 \mathrm{E}-06$ & $2,92 \mathrm{E}-06$ \\
1.0 & $3,54 \mathrm{E}-06$ & $3,54 \mathrm{E}-06$ & $4,25 \mathrm{E}-06$ & $4,25 \mathrm{E}-06$ & $4,96 \mathrm{E}-06$ & $4,96 \mathrm{E}-06$
\end{tabular}

\section{Results and Discussion}

In this study, static deflection, inclination and bending moment distributions in the beam were investigated in the static study of non-local FG nano beams subjected to end and lateral applied forces. It is assumed that the beam's modulus of elasticity changes exponentially. In addition, $\mathrm{E}_{1}=1 \mathrm{nN} / \mathrm{m}^{2}, \mathrm{e}_{0} \mathrm{a}=1 \mathrm{~nm}, \mathrm{I}=1 \mathrm{~nm}^{4}, \mathrm{P}_{1}=\mathrm{P}_{2}=1.2 \mathrm{nN}$ in calculations. By applying extreme axial forces to the FG nano beam, it has been tried to obtain information about the effect of bending on its mechanical behavior. Figure 2 was created to see the effect of inhomogeneity parameter on deflection in cantilever FG nano beam subjected to end lateral and axial forces. 


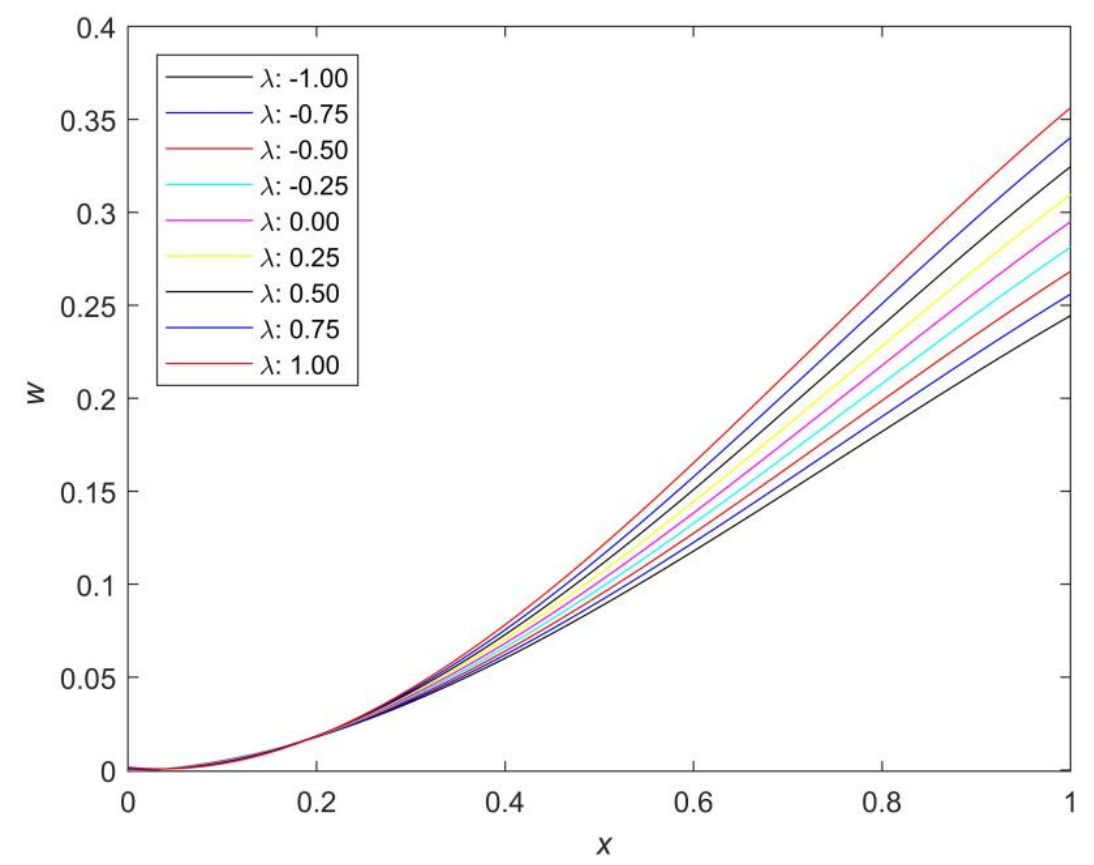

Fig. 2. Static deflection for end lateral and axial forces

When Figure 2 is examined, it is noted that the static deviation value rises with the rise in the distance from the fixed end and the static deviation rises with the rise in the inhomogeneity constraint. Figure 3 shows the impacts of end and lateral forces on the curvature of the cantilever FG nano-beam.

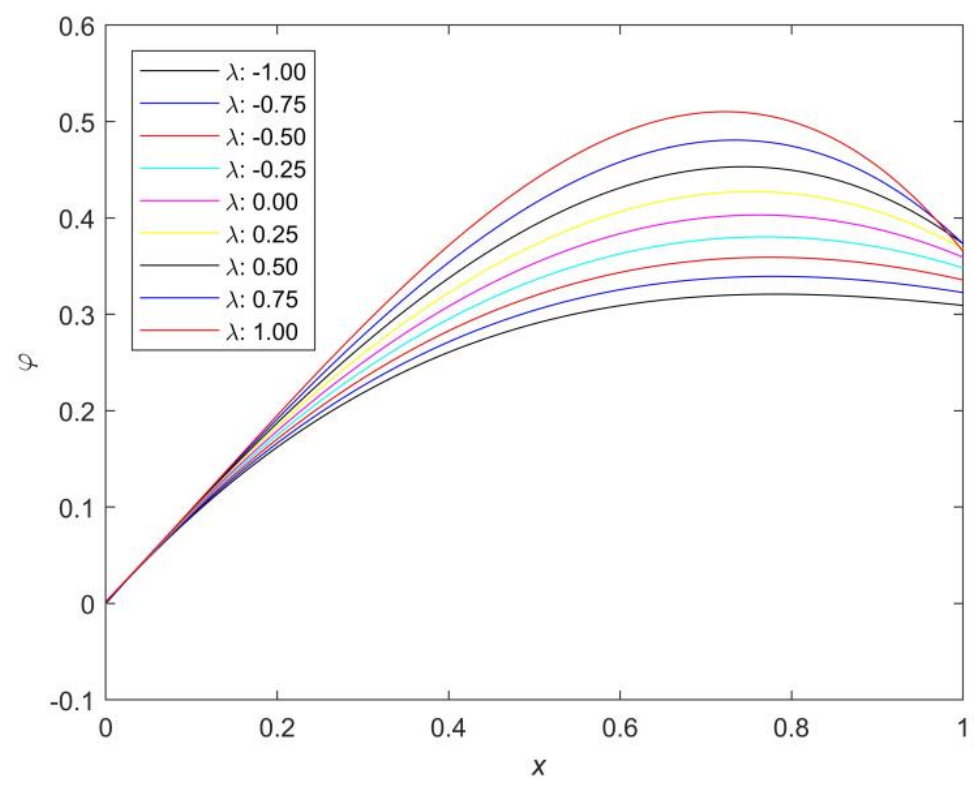

Fig. 3. Slope for end and lateral forces

Figure 3 shows the rise and decline in slope with increasing distance from the tip, emphasizing the importance of tip lateral concentrated forces. It can also be concluded that the higher values of the inhomogeneity constraint increase the slope considerably. 
The impacts of end loads on the bending moment of FG cantilever nano-beams are presented in Figure 4. Again, in adding to the axial and lateral forces, the impacts of the inhomogeneity parameter on the bending moment are very clear.

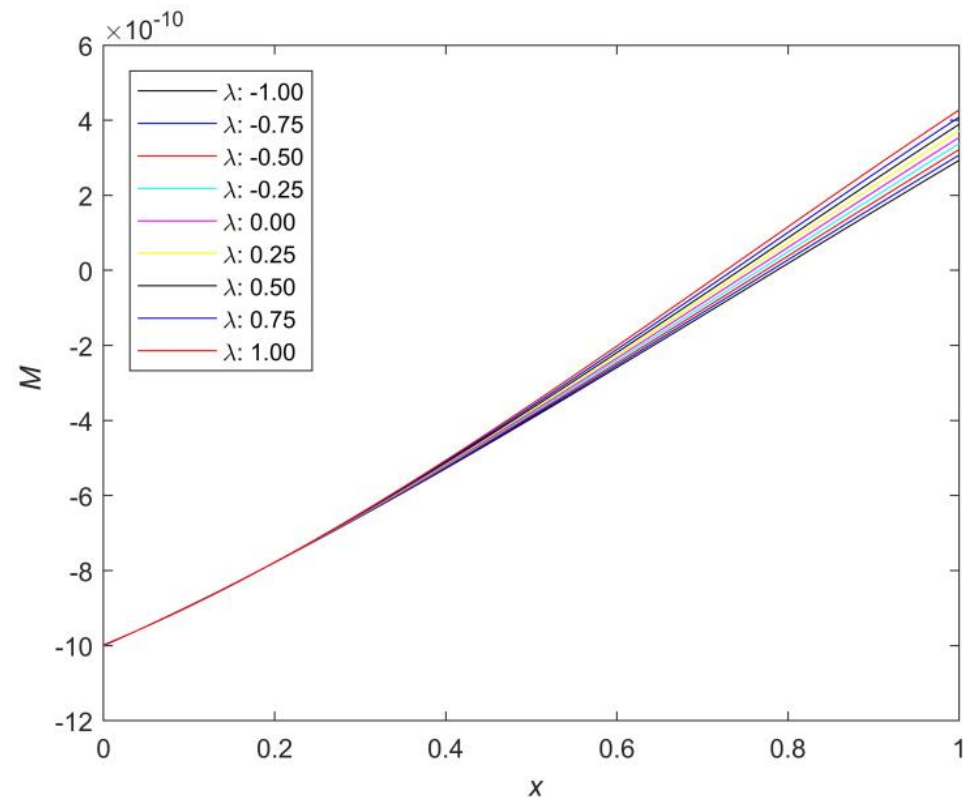

Fig. 4. Moment diagram for constant end and axial forces

\section{Conclusion}

In this study, it has been shown that PCM can be applied to the solution of the nonlocal primary worth problem involving homogeneous linear differential equalities. The FG nanotube was modeled as a beam with the Euler-Bernoulli theory. For the small-scale effect, the nonlocal elasticity theory is used. The results obtained and the methodology presented in this research can be used as an aid in the design and analysis of FG nanobeams. Therefore, it can be concluded:

- It has been determined that the homogeneity parameters have a strong effect on the static deflection, tilt and bending moment distribution.

- PCM has a high-level correctness rate with low computational cost due to its dense mesh structure close to the border and its rough structure towards the center points. Therefore, it can be used as a practical solution tool in solving such problems.

- It provides an effective performance when the inhomogeneity parameter is high when a functionally graded nano beam operates under the effect of end and lateral forces.

\section{References}

[1] Aydogdu, M., Taskin, V., Free vibration analysis of functionally graded beams with simply supported edges, Materials \& design, 28(5), 1651-1656, 2007.

[2] Chakraborty, A., Gopalakrishnan, S., Reddy, J.N., A new beam finite element for the analysis of functionally graded materials, International journal of mechanical sciences, 
45(3), 519-539, 2003.

[3] Ke, L. L., Yang, J., Kitipornchai, S., Xiang, Y., Flexural vibration and elastic buckling of a cracked Timoshenko beam made of functionally graded materials. Mechanics of Advanced Materials and Structures, 16(6), 488-502, 2009.

[4] Li, X.F., A unified approach for analyzing static and dynamic behaviors of functionally graded Timoshenko and Euler-Bernoulli beams. J Sound Vib., 318(4-5), 1210-1229, 2008.

[5] Sina, S.A., Navazi, H.M., Haddadpour, H., An analytical method for free vibration analysis of functionally graded beams, Mater Des, 30(3), 741-747, 2009.

[6] Şimşek, M., Static analysis of a functionally graded beam under a uniformly distributed load by Ritz method, Int J Eng Appl Sci., 1(3), 1-11, 2009.

[7] Şimşek, M., Dynamic analysis of an embedded microbeam carrying a moving microparticle based on the modified couple stress theory, Int J Eng Sci., 48(12), 1721$1732,2010$.

[8] Şimşek, M., Fundamental frequency analysis of functionally graded beams by using different higher-order beam theories, Nucl Eng Des., 240(4), 697-705, 2010.

[9] Şimşek, M., Vibration analysis of a functionally graded beam under a moving mass by using different beam theories, Compos Struct., 92(4), 904-917, 2010.

[10] Şimşek, M., Non-linear vibration analysis of a functionally graded Timoshenko beam under action of a moving harmonic load, Compos Struct., 92(10), 2532-2546, 2010.

[11] Şimşek, M., Kocatürk T., Akbaş Ş.D., Static bending of a functionally graded microscale Timoshenko beam based on the modified couple stress theory, Compos Struct., 95(1), 740 747, 2013.

[12] Thai, H.T., Vo, T.P., Bending and free vibration of functionally graded beams using various higher-order shear deformation beam theories, Int J Mech Sci., 62(1), 57-66, 2012.

[13] Ying, J., Lü, C.F., Chen, W.Q., Two-dimensional elasticity solutions for functionally graded beams resting on elastic foundations, Compos Struct., 84(3), 209-219, 2008.

[14]Lü, C.F., Lim, C.W., Chen, W.Q., Size-dependent elastic behavior of FGM ultra-thin films based on generalized refined theory, Int J Solids Struct., 46(5), 1176-1185, 2009.

[15]Zhong, Z., Yu, T., Analytical solution of a cantilever functionally graded beam, Compos Sci Technol., 67(3-4), 481-488, 2007.

[16]Eringen, A.C., Nonlocal polar elastic continua, Int J Eng Sci., 10(1), 1-16, 1972.

[17]Eringen, A.C., Edelen, D.G.B., On nonlocal elasticity, Int J Eng Sci., 10(3), 233-248, 1972.

[18] Aydogdu, M., A general nonlocal beam theory: its application to nanobeam bending, buckling and vibration, Phys E Low-Dimensional Syst Nanostructures, 41(9), 1651-1655, 2009.

[19]Liu, T., Hai, M., Zhao, M., Delaminating buckling model based on nonlocal Timoshenko beam theory for microwedge indentation of a film/substrate system, Eng Fract Mech., 75(17), 4909-4919, 2008.

[20]Reddy, J.N., Nonlocal theories for bending, buckling and vibration of beams, Int J Eng Sci., 45(2-8), 288-307, 2007. 
[21] Narendar, S., Buckling analysis of micro-/nano-scale plates based on two-variable refined plate theory incorporating nonlocal scale effects, Compos Struct., 93(12), 3093-3103, 2011.

[22]Pradhan, S.C., Phadikar, J.K., Nonlocal elasticity theory for vibration of nanoplates, J Sound Vib., 325(1-2), 206-223, 2009.

[23] Shen, L.E., Shen, H.S., Zhang, C.L., Nonlocal plate model for nonlinear vibration of single layer graphene sheets in thermal environments, Comput Mater Sci., 48(3), 680-685, 2010.

[24] Mercan, K., Civalek, Ö., Buckling analysis of silicon carbide nanotubes (SiCNTs), Int J Eng Appl Sci., 8(2), 101-108, 2016.

[25] Mercan, K., Demir, Ç., Akgöz, B., Civalek, Ö., Coordinate transformation for sector and annular sector shaped graphene sheets on silicone matrix, Int J Eng Appl Sci., 7(2), 56-73, 2015.

[26] Mercan, K., Civalek, Ö., DSC method for buckling analysis of boron nitride nanotube (BNNT) surrounded by an elastic matrix, Compos Struct., 143(1), 300-309, 2016.

[27] Gürses, M., Akgöz, B., Civalek, Ö., Mathematical modeling of vibration problem of nanosized annular sector plates using the nonlocal continuum theory via eight-node discrete singular convolution transformation, Appl Math Comput., 219(6), 3226-3340, 2012.

[28] Yayl1, M.Ö., Buckling analysis of a rotationally restrained single walled carbon nanotube embedded in an elastic medium using nonlocal elasticity, Int J Eng Appl Sci., 8(2), 40-50, 2016.

[29] Yaylı, M.Ö., An analytical solution for free vibrations of a cantilever nanobeam with a spring mass system, Int J Eng Appl Sci., 7(4), 10-18, 2016.

[30] Wang, Q., Shindo, Y., Nonlocal continuum models for carbon nanotubes subjected to static loading, J Mech Mater Struct., 1(4), 663-680, 2006.

[31] Nazmul, I.M., Devnath, I., Exact analytical solutions for bending of bi-directional functionally graded nanobeams by the nonlocal beam theory using the Laplace transform, Forces Mech., 1(1), 100002, 2020.

[32] Akgöz, B., Civalek, Ö., Vibrational characteristics of embedded microbeams lying on a two-parameter elastic foundation in thermal environment, Compos Part B Eng., 150(1), 68-77, 2018.

[33]Dastjerdi, S., Akgöz, B., New static and dynamic analyses of macro and nano FGM plates using exact three-dimensional elasticity in thermal environment, Compos Struct., 192(1), 626-641, 2018.

[34] Akgöz, B., Civalek, Ö., Investigation of size effects on static response of single-walled carbon nanotubes based on strain gradient elasticity, Int J Comput Methods, 9(2), 1240032, 2012.

[35] Mercan, K., Numanoglu, H.M., Akgöz, B., Demir, C., Civalek, Ö., Higher-order continuum theories for buckling response of silicon carbide nanowires (SiCNWs) on elastic matrix, Arch Appl Mech., 87(11), 1797-1814, 2017.

[36] Civalek, Ö., Kiracioglu, O., Free vibration analysis of Timoshenko beams by DSC method, Int j Numer Method Biomed Eng., 26(12), 1890-1898, 2010. 
[37] Sciarra, F.M.D., Finite element modelling of nonlocal beams, Phys E., 59(1), 144-149, 2014.

[38]Nguyen, N.T., Kim, N.I., Lee, J., Mixed finite element analysis of nonlocal EulerBernoulli nanobeams, Finite Elem Anal Des., 106(1), 65-72, 2015.

[39] Wang, Q., Wave propagation in carbon nanotubes via nonlocal continuum mechanics, J Appl Phys., 98(12), 124301, 2005.

[40]Artan, R., Tepe, A., The initial values method for buckling of nonlocal bars with application in nanotechnology, Eur J Mech., 27(3), 469-477, 2008.

[41] Yayl1, M.Ö., Kandemir, S.Y., Bending analysis of a cantilever Nanobeam with end forces by Laplace transform, Int J Eng Appl Sci., 9(2), 103-111, 2017.

[42] Nihat, C., Kurgan, N., Hassan, A.H.A., Buckling Analysis of Functionally Graded Plates Using Finite Element Analysis, Int J Eng Appl Sci., 12(1), 43-56, 2020.

[43] Peddieson, J., Buchanan, G.R., McNitt, R.P., Application of nonlocal continuum models to nanotechnology, Int J Eng Sci., 41(3-5), 305-312, 2003.

[44] Trefethen, L.N., Spectral methods in MATLAB, volume 10 of Software, Environments, and Tools, Soc Ind Appl Math (SIAM), Philadelphia, PA 2000.

[45]Fornberg, B., A practical guide to pseudospectral methods, Cambridge university press, 1998.

[46] Gottlieb, D., The stability of pseudospectral-Chebyshev methods, Math Comput., 36(153), 107-118, 1981. 